\title{
Manifestaciones orales de trastornos hematológicos no neoplásicos.
}

\author{
Oral manifestations of non-neoplastic hematologic disorders.
}

\author{
Israel Parra Ortega,* Daniel Rodríguez Ortega ${ }^{\ddagger}$
}

\section{RESUMEN}

Las alteraciones hematológicas pueden tener el primer signo en la cavidad oral y los signos varían dependiendo de la línea celular que se encuentre afectada: eritrocitos, leucocitos y plaquetas. La formación de las células sanguíneas se lleva a cabo en la médula ósea a través de un proceso denominado hematopoyesis que se encarga de la formación, desarrollo y especialización de todas sus células sanguíneas funcionales, pasan de células troncales pluripotenciales a células hematopoyéticas maduras que emergen a la sangre periférica. El odontólogo debe ser capaz de identificar los distintos signos en la cavidad oral que podrían sugerir que el paciente padece un trastorno hematológico, el cual podría complicar el tratamiento dental. La identificación oportuna de estos signos a través de una minuciosa exploración física y la historia clínica completa evita que se presenten complicaciones en el paciente y que éstas puedan poner en riesgo su vida, por lo que al encontrar algún signo sugerente de un trastorno hematológico debe referirse al paciente con el hematólogo.

Palabras clave: Eritrocitos, leucocitos, plaquetas, úlcera, sangrado, periodontopatías.

\section{ABSTRACT}

Hematological alterations may be the first sign in the oral cavity and symptoms vary depending on the cell line that is affected: Erythrocytes, leukocytes and platelets. The formation of blood cells are held in the bone marrow through a process called hematopoiesis, which is responsible for training, development and specialization in all its functional blood cells, they move from pluripotent stem cell to hematopoietic cells mature emerging to peripheral blood. The dentist must be able to identify the different signs in the oral cavity that could suggest that the patient has a haematological disorder, which could complicate dental treatment. The timely identification of these signs through a thorough physical examination and the complete clinical history prevents complications from occurring in the patient and may put their lives at risk, so when finding any sign suggestive of a hematological disorder should refer to the patient with the hematologist.

Keywords: Erythrocytes, leukocytes, platelets, ulcer, bleeding, periodontopathies.

\section{INTRODUCCIÓN}

L as enfermedades sistémicas pueden provocar mani$\checkmark$ festaciones clínicas en el área oral y maxilofacial, en ocasiones como un signo primario inespecífico de una enfermedad subyacente no diagnosticada. ${ }^{1}$ Hay diferentes signos en la cavidad oral que pueden deberse a un trastorno hematológico y dependerán de la línea celular que se encuentre afectada..$^{1-3}$

El odontólogo debe ser capaz de identificar los distintos signos en la cavidad oral que podrían sugerir que el paciente padece un trastorno hematológico, el cual podría complicar el tratamiento dental (sangrados, infecciones recurrentes, et-

\footnotetext{
* Jefe de Laboratorio Clínico, Hospital Infantil de México «Federico Gómez», CDMX.

‡ Estudiante de Odontología, Centro Interdisciplinario de Ciencias de La Salud UST IPN. CDMX.

Recibido: 25 Septiembre 2019.

Aceptado para publicación: 18 Noviembre 2019.
}

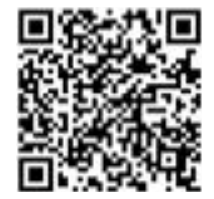

cétera). La identificación oportuna de estos signos a través de una minuciosa exploración física y la historia clínica completa evita que se presenten complicaciones en el paciente y que éstas puedan poner en riesgo su vida, por lo que al encontrar algún signo sugerente de un trastorno hematológico debe referirse al paciente con el hematólogo. 1,2,4,5

Para entender los signos y síntomas de los trastornos hematológicos se debe comprender cómo se originan los elementos formes de la sangre. La sangre forma parte del tejido conectivo que se compone por una matriz extracelular líquida llamada plasma, en la cual se disuelven diversas sustancias (proteínas, agua y solutos) y se encuentran numerosas células y fragmentos celulares en suspensión. ${ }^{6}$ Circula a través del sistema vascular que es bombeado por el corazón para que llegue a todo el organismo. La formación de los elementos formes de la sangre se lleva a cabo a través de un proceso denominado hematopoyesis que se encarga de la formación, desarrollo y la especialización de todas sus células sanguíneas funcionales, pasan 
de células troncales pluripotenciales a células hematopoyéticas maduras que emergen a la sangre periférica, y su producción depende de las necesidades del organismo. En la sangre se pueden identificar tres grupos celulares: eritrocitos (ER), leucocitos (LE) y plaquetas (PLA). 4,7-10

\section{TRASTORNOS DE LOS ERITROCITOS}

Los ER o glóbulos rojos son células anucleadas que en su interior contienen la proteína hemoglobina que transporta el oxígeno desde los pulmones a todos los tejidos del cuerpo. ${ }^{6,10,11}$ Se forman a partir del proceso denominado eritropoyesis, que es regulado por el riñón mediante la liberación de la hormona eritropoyetina, la cual detecta la concentración de oxígeno en la sangre circulante y responden a la hipoxia tisular, que estimula a la médula aumentando el proceso de eritropoyesis. $4,9,10$

Los trastornos de los ER son causados por múltiples factores y provocan un desequilibrio entre la eritropoyesis y la utilización, destrucción o eliminación de los eritrocitos, o cuando el ER no produce o almacena suficiente cantidad de hemoglobina (Tabla 1). 4,7,10

\section{Anemia con alteración en el metabolismo del hierro}

\section{Anemia ferropénica (deficiencia de hierro)}

Es causada por un consumo dietético inadecuado, pérdida hemática crónica, malabsorción en el tubo digestivo (enfermedad celíaca, resección de estómago o intestino)

Tabla 1: Trastornos de los eritrocitos. . $^{1,3,4,6,7,10-32}$

\begin{tabular}{|c|c|c|}
\hline & & Manifestaciones orales \\
\hline \multirow[t]{2}{*}{$\begin{array}{l}\text { Anemia con alteración } \\
\text { en el metabolismo del } \\
\text { hierro }\end{array}$} & $\begin{array}{l}\text { Anemia ferropénica } \\
\text { (deficiencia de hierro) }\end{array}$ & $\begin{array}{l}\text { Tejidos mucosos pálidos y atróficos, lengua depapilada, glositis, } \\
\text { queilitis angular, candidiasis oral, retraso en la curación de heridas } \\
\text { después de una cirugía bucal, úlceras, glosodinia y disfagia }\end{array}$ \\
\hline & $\begin{array}{l}\text { Síndrome de Plummer-Vinson o } \\
\text { de Paterson-Kelly }\end{array}$ & $\begin{array}{l}\text { Atrofia de la mucosa del esófago con formación de membranas que } \\
\text { provocan disfagia, glositis atrófica, queilitis angular y glosodinia }\end{array}$ \\
\hline \multirow[t]{3}{*}{ Anemia megaloblástica } & Anemia perniciosa & $\begin{array}{l}\text { Glosodinia, ageusia, mucosa oral pálida y ulcerada, glositis dolorosa de } \\
\text { Moeller-Hunter por atrofia gradual de las papilas filiformes fungiformes } \\
\text { que confiere un aspecto liso, rojo y brillante en la superficie dorsal }\end{array}$ \\
\hline & Deficiencia de cobalamina (B12) & $\begin{array}{l}\text { Después se pierde el tono muscular de la lengua y aparece roja e infla- } \\
\text { mada, con lesiones eritematosas maculares en la punta y los bordes }\end{array}$ \\
\hline & $\begin{array}{l}\text { Anemia por deficiencia de ácido } \\
\text { fólico }\end{array}$ & $\begin{array}{l}\text { Mucosa oral pálida y ulcerada, atrofia del epitelio lingual, queilitis } \\
\text { comisural, estomatitis ulcerativa y faringitis }\end{array}$ \\
\hline \multirow[t]{2}{*}{$\begin{array}{l}\text { Alteración de la } \\
\text { hemoglobina }\end{array}$} & $\beta$-talasemia mayor & $\begin{array}{l}\text { Anemia grave, aumento del díploe craneal con trabéculas que se disponen } \\
\text { en forma perpendicular a las tablas externa e interna (cráneo en cepillo), } \\
\text { biprotrusión maxilar, prominencia de los huesos cigomáticos, diastemas, } \\
\text { eminencias malares evidentes, mordida abierta, palidez de la mucosa oral, } \\
\text { hipertelorismo orbital, obliteración de los senos paranasales, erupción tar- } \\
\text { día, aumento de tamaño de los espacios de la médula ósea, raíces dentales } \\
\text { cortas, taurodontismo y dolor e inflamación de las glándulas parótidas }\end{array}$ \\
\hline & $\begin{array}{l}\text { Anemia drepanocítica } \\
\text { (células falciformes) }\end{array}$ & $\begin{array}{l}\text { Palidez e ictericia cutánea y de mucosas, predisposición a las infec- } \\
\text { ciones, radiográficamente trabéculas óseas en «escalera» con zonas } \\
\text { de esclerosis y radiolucidez en dientes posteriores, osteólisis de leve } \\
\text { a severa, espacios medulares amplios e irregulares, osteomielitis } \\
\text { mandibular (debido al poco aporte vascular), retraso en la erupción e } \\
\text { hipoplasia de la dentición permanente }\end{array}$ \\
\hline Anemia aplásica & \multicolumn{2}{|c|}{$\begin{array}{l}\text { Palidez de la mucosa yugal, infecciones orales y periodontales graves (periodontitis) con gingivorragias } \\
\text { espontáneas, petequias, equimosis, candidiasis y aftas recurrentes como signos tempranos de la enfermedad. } \\
\text { Los signos que indican mayor avance de la enfermedad son hiperplasia gingival y lesiones herpéticas }\end{array}$} \\
\hline
\end{tabular}


o incremento de la demanda de hierro (embarazo, infancia). Lo que causa que el ER sea incapaz de portar una cantidad normal de oxígeno. 4,12,15 Según datos de la Organización Mundial de la Salud (OMS), más de dos billones de personas tienen deficiencia de hierro, lo que representa casi $25 \%$ de la población mundial. ${ }^{15}$ Las manifestaciones orales son palidez en piel y mucosas debido a la reducción de ER, también el recambio celular se disminuye provocando atrofia en las mucosas, retraso en la curación de heridas después de una cirugía bucal, atrofia gradual o en placas de las papilas filiformes o fungiformes linguales dándole al dorso de la lengua un aspecto liso, rugoso y brillante. En algunos casos también se puede presentar disfagia y queilitis angular. ${ }^{1,4,12-15}$

\section{Síndrome de Plummer-Vinson}

Es una condición clínica rara que se caracteriza por la triada de disfagia, presencia de membranas esofágicas y anemia ferropénica crónica. ${ }^{3,16}$ Los factores relacionados con su etiología son la anemia ferropénica, desnutrición, predisposición genética, procesos autoinmunes y otras deficiencias de nutrientes (piridoxina o la riboflavina). ${ }^{16,17}$ Se ha reportado en todas partes del mundo y comúnmente se presenta en mujeres blancas de complexión delgada durante la mediana edad. ${ }^{16}$ Las manifestaciones orales son atrofia de la mucosa del esófago con formación de membranas que provocan disfagia (síntoma común), pero también puede presentar glositis atrófica, queilitis angular y glosodinia. El 10\% de los pacientes desarrolla carcinoma de células escamosas principalmente en hipofaringe y esófago. ${ }^{17-20}$

\section{Anemias megaloblásticas}

Son un grupo de anemias en las que los progenitores de los hematíes de la médula ósea presentan alteración en la síntesis de ácido desoxirribonucleico (ADN), la causa más frecuente es debida a la carencia de vitamina B12 o de ácido fólico:

- Deficiencia de vitamina B12 (anemia perniciosa): la vitamina B12 es sintetizada por bacterias intestinales, pero se pierde en su mayor parte por las heces, cuando es ingerida es separada de las proteínas debido al $\mathrm{pH}$ ácido del estómago y a las enzimas pancreáticas. Un vez libre, se une al factor intrínseco producido por las células parietales del estómago, lo que permite que sea absorbida (pase a la sangre) en el último tramo del intestino delgado (íleon).
Los depósitos de vitamina B12 se localizan en el hígado y son muy abundantes, lo que hace que su deficiencia tarde años en manifestarse. La principal alteración que se presenta es la anemia perniciosa, es una afección autoinmunitaria que se distingue por la incapacidad de la mucosa gástrica para sintetizar el factor intrínseco $(\mathrm{Fl})$, necesario para transportar la vitamina B12 a través de la mucosa intestinal debido a la presencia de anticuerpos dirigidos contras las células parietales y/o contra el factor intrínseco, lo que produce una gastritis crónica atrófica (autoinmune o tipo A) en el cuerpo y fundus del estómago. También otros factores que pueden derivar de la deficiencia de esa vitamina es el consumo dietético inadecuado, síndromes de malabsorción, alcoholismo y trastornos pancreáticos. ${ }^{21,22}$ La prevalencia en países industrializados es aproximadamente de $20 \%$ de la población. ${ }^{23}$ La ausencia de esta vitamina provoca que se presente una reducción en la síntesis de ácidos nucleicos y una reducción de la división celular. Las manifestaciones orales a consecuencia de esta ausencia causan un disminución de la proliferación epitelial con el signo de glositis de Hunter: depapilación de la lengua con una capa eritematosa, lo que le confiere a la lengua un aspecto liso, rojo y brillante en la superficie dorsal. También pueden presentar queilitis angular (asociado a candidiasis concomitante) y úlceras de tipo aftoso. ${ }^{1,4,12,16}$

- Deficiencia de ácido fólico: presenta las mismas características patológicas que la ausencia de vitamina B12 y se debe al consumo inadecuado o el requerimiento creciente de esa sustancia (embarazo, lactancia, infancia y adolescencia) que hace que el consumo sea insuficiente. También puede ser causado por síndromes de malabsorción, alcoholismo o una enfermedad neoplásica. Se presenta con mayor incidencia en mujeres, ancianos y personas hospitalizadas por el aporte inadecuado de este nutriente. Las manifestaciones orales son queilitis comisural, estomatitis ulcerativa y faringitis. Debido a la disfunción de las células B y T son pacientes más susceptibles a infecciones orales secundarias. ${ }^{1,4,12,16}$

\section{Alteración de la hemoglobina}

\section{Talasemias}

Son un grupo heterogéneo de anemias hereditarias que afectan la síntesis de las cadenas $\alpha$ (alteración en el cromosoma 16) y $\beta$ (alteración en el cromosoma 11) de globina, 
lo que provoca un desequilibrio entre ambas y la acumulación intraeritrocitaria de la cadena que se encuentra en exceso. Cada tipo de talasemia recibe el nombre de la cadena que deja de sintetizarse y su expresividad clínica es muy variable; depende de la alteración molecular y puede variar desde una nula expresividad clínica hasta la complicaciones más severas. ${ }^{4,12,24,25}$ Representan el desorden genético más común y se estima que $5 \%$ de la población mundial es portadora de un gen mutado para la hemoglobina. ${ }^{25-27}$ Los pacientes con talasemia $\beta$ menor e intermedia y las variedades más leves de talasemia $\alpha$ pueden carecer de anomalías orales, excepto por la posible palidez de los tejidos blandos. ${ }^{4}$

La talasemia $\beta$ mayor puede ocasionar palidez en la mucosa oral, cambios en el patrón trabecular de los huesos orales y craneales, hipertelorismo orbital, la mandíbula puede mostrar mayor radiolucidez y un patrón trabecular en panal, mientras que la superficie del cráneo corresponde al signo de «cabello de punta» característica de la talasemia $\beta$ mayor. También el hueso cigomático y el maxilar se hacen más prominentes, y se puede observar el espaciamiento y la separación anómalos de los incisivos del maxilar. La lamina dura puede ser delgada o faltar en algunas regiones y a veces se puede presentar prominencia del hueso frontal. $1,4,9,26$

\section{Anemia drepanocítica (anemia de células falciformes)}

Es una alteración genética autosómica recesiva que conlleva a la producción anómala de la hemoglobina. Se presenta una alteración en el brazo corto del cromosoma 11 causado por una sustitución del aminoácido valina por ácido glutámico en la sexta posición de la cadena $\beta$ de la hemoglobina. Como resultado se produce hemoglobina $S$ haciendo que el ER tenga una morfología de hoz lo que provoca la hemólisis del ER y la oclusión de los vasos sanguíneos. ${ }^{28,29}$ En México se ha notificado una frecuencia variable en individuos mestizos, desde menos de $1 \%$ en el centro del país hasta más de $14 \%$ en las costas, algo atribuible al factor de la mezcla con sujetos de origen africano. ${ }^{30}$ Las manifestaciones orales son palidez e ictericia cutánea y de mucosas como consecuencia de la hemólisis del ER, aumento en la predisposición de las infecciones y es frecuente que se observen alteraciones en las radiografías dentales y de cráneo. En las radiografías de cráneo se puede observar díploe craneal engrosado con múltiples espículas que dan a la calota el denominado «aspecto erizado». En las radiografías dentales es frecuente observar trabéculas óseas en «escalera» con zonas de esclerosis y radiolucidez en dientes posteriores adyacentes y una lámina dura densa. También se puede presentar retraso en la erupción e hipoplasia de la dentición permanente, en menor medida pero con casos reportados de osteomielitis mandibular (causado por el poco aporte vascular a este hueso) y necrosis pulpar asintomática debida a la estasis y oclusión vascular. ${ }^{1,4,11}$

\section{Anemia aplásica}

También denominada aplasia medular, es una anomalía adquirida que provoca la destrucción o lesión de las células troncales pluripotenciales de donde se originan todos los elementos celulares de la sangre. La alteración provoca una disminución celular importante, pero no de forma uniforme de todos los linajes hematopoyéticos porque depende del grado de hipoplasia medular. ${ }^{31,32}$ Su etiología puede ser por varios factores, $80 \%$ es adquirido (sustancias químicas, medio ambiente, microorganismos o enfermedades) y $20 \%$ es congénito o hereditario. ${ }^{10}$ Las manifestaciones orales son palidez de la mucosa yugal, infecciones orales y periodontales graves con gingivorragias espontáneas, petequias, equimosis, candidiasis y úlceras recurrentes como signos tempranos de la enfermedad. Los signos que indican mayor avance de la enfermedad son hiperplasia gingival, lesiones herpéticas. ${ }^{1,4,11,31}$

\section{TRASTORNOS DE LOS LEUCOCITOS}

Los LE son componentes celulares de la sangre que se forman en la médula ósea a partir de las células troncales pluripotenciales igual que los eritrocitos. Su diferenciación conlleva la formación de una célula troncal linfoide que da origen a los leucocitos y una célula troncal mieloide que permite el desarrollo de monocitos, granulocitos, plaquetas y eritrocitos. Las alteraciones presentan distintos cuadros clínicos que dependen de la etiología (Tabla 2).4,33

\section{Deficiencia cuantitativa}

\section{Neutropenias o agranulocitosis adquiridas}

El término indica un conteo bajo de neutrófilos circulantes. Las causas más frecuentes es una reacción farmacológica adversas, pero también puede ser causado por trastornos hereditarios, infecciones virales o bacterianas incontenibles, autoinmune, neoplasia de la medula ósea y anemia. ${ }^{1,4,7,34}$ Las manifestaciones orales son periodontitis agresiva frecuente y presencia de úlceras necróticas (grandes, irregulares, profundas y dolorosas) recubiertas 


\section{Tabla 2: Trastornos de los leucocitos. $1,4,7,10,33,34$}

\begin{tabular}{|c|c|c|}
\hline & & Manifestaciones orales \\
\hline \multirow[t]{3}{*}{ Deficiencia cuantitativa } & Neutropenia o agranulocitosis & $\begin{array}{l}\text { Periodontitis agresiva frecuente y úlceras necróticas (grandes, } \\
\text { irregulares, profundas y dolorosas) recubiertas por pseudomembra- } \\
\text { nas de un color blanco-grisáceo. Estas úlceras pueden ser múltiples } \\
\text { y miden desde } 0.5 \text { a varios centímetros de diámetro. Las zonas más } \\
\text { afectadas son el paladar, las encías, la lengua y las amígdalas, pueden } \\
\text { provocar disfagia y sialorrea }\end{array}$ \\
\hline & Neutropenia cíclica & $\begin{array}{l}\text { Pérdida prematura de dientes, úlceras recurrentes profundas y grandes } \\
\text { que persisten, están recubiertas por una pseudomembrana blanquecina } \\
\text { rodeada de eritema leve. La afección periodontal se puede presentar } \\
\text { como gingivitis o periodontitis, estomatitis con ulceración }\end{array}$ \\
\hline & $\begin{array}{l}\text { Síndrome Kostmann o } \\
\text { agranulocitosis genética infantil }\end{array}$ & $\begin{array}{l}\text { Úlceras aftosas dolorosas, recurrentes y persistentes, infecciones } \\
\text { bacterianas, candidiasis, periodontitis y gingivitis frecuentes, las encías } \\
\text { marginal y adherida se aprecian edematosas, y las papilas interdentales } \\
\text { hiperplásicas }\end{array}$ \\
\hline \multirow[t]{3}{*}{ Alteración funcional } & $\begin{array}{l}\text { Enfermedad granulomatosa } \\
\text { crónica }\end{array}$ & $\begin{array}{l}\text { Candidiasis, eritema y ulceraciones con pseudomembranas en } \\
\text { cualquier parte de la mucosa oral, sinusitis recurrentes, linfadenitis } \\
\text { cervical, queilitis eccematosa, gingivitis intensa, lengua geográfica, } \\
\text { hipoplasia del esmalte, caries rampantes e infecciones cutáneas faciales }\end{array}$ \\
\hline & Leucocito perezoso & $\begin{array}{l}\text { Infecciones frecuentes, un ejemplo es la aparición de estomatitis, gin- } \\
\text { givitis, ulceraciones recurrentes y enfermedad periodontal agresiva }\end{array}$ \\
\hline & Síndrome de Chédiak-Higashi & $\begin{array}{l}\text { Periodontitis agresiva, movilidad dentaria, supuración, bolsas perio- } \\
\text { dontales profundas, glositis, hemorragia gingival y ulceraciones de la } \\
\text { mucosa oral }\end{array}$ \\
\hline
\end{tabular}

por pseudomembranas de un color blanco-grisáceo. Estas úlceras pueden ser múltiples y miden desde 0.5 a varios centímetros de diámetro. Las zonas más afectadas son el paladar, las encías, la lengua y las amígdalas, pueden provocar disfagia y sialorrea. 4,35

\section{Neutropenia cíclica}

Es una alteración que presenta disminución periódica en el número de neutrófilos con duración de entre tres y seis días. Es poco frecuente y se caracteriza por episodios habituales de fiebre. Su etiología puede ser adquirida por medicamentos (anticonvulsivos, antihistamínicos, barbitúricos, diuréticos, sulfamidas) o congénito (enfermedad de Kostmann, síndrome de Shwachman o mielocatexis). Es resultado de la mutación del gen EIA2 posición 13.3 del brazo corto del cromosoma 19 que codifica la elastasa neutrofílica. Existe una interrupción en la producción de las células troncales de la médula ósea; esto causa el efecto del fenómeno cíclico, lo que provoca desde una producción normal hasta un severo estancamiento en la maduración del neutrófilo. ${ }^{36}$ En la incidencia se presentan dos casos por un millón de habitantes. Las manifestaciones orales son pérdida prematura de dientes, úlceras (recurrentes, profundas, grandes y persistentes) recubiertas por una pseudomembrana blanquecina rodeada de eritema leve. La afección periodontal se puede presentar como gingivitis o periodontitis acompañada de ulceraciones. ${ }^{4,34-36}$

\section{Alteración funcional}

\section{Enfermedad granulomatosa crónica}

Inmunodeficiencia primaria de la fagocitosis, tiene una incidencia mundial de uno por cada 250,000 recién nacidos vivos. Su etiología está ligado a la mutación en cualquiera de los genes que codifican para las subunidades que conforman la enzima NADPH-oxidasa, por lo cual se disminuye la capacidad fagocitaria de los polimorfo- 
nucleares y monocitos. ${ }^{37}$ Las manifestaciones orales son candidiasis, eritema y ulceraciones con pseudomembranas en cualquier parte de la mucosa oral, sinusitis recurrentes, linfadenitis cervical, retraso en la cicatrización o dehiscencia de las heridas, queilitis eccematosa, gingivitis intensa, lengua geográfica, hipoplasia del esmalte, caries rampantes e infecciones cutáneas faciales. 1,37-39

\section{Síndrome del leucocito perezoso}

Es un trastorno genético raro, causado por una alteración en la función quimiotáctica de los neutrófilos, en el que las células poseen movimientos azarosos y sin dirección. ${ }^{9}$ Se presenta en los primeros años de vida. Las manifestaciones clínicas son un incremento en la predisposición a las infecciones, siendo frecuente la aparición de estomatitis, gingivitis, ulceraciones recurrentes y enfermedad periodontal agresiva. ${ }^{1,40}$

\section{Sindrome de Chédiak-Higashi}

Es una deficiencia inmune de carácter autosómico recesivo que se origina por mutaciones del gen 1q42 que codifica la proteína lysosomal trafficking regulator (LYST); esta proteína se encarga de la regulación del transporte lisosomal y la función del citoesqueleto, lo cual afecta la función de los leucocitos. El 85\% de los casos se presenta en la etapa infantil. ${ }^{41,42}$ Las manifestaciones orales principalmente son la periodontitis agresiva (caracterizada con movilidad dentaria), bolsas periodontales profundas con supuración, hemorragia gingival, glositis y ulceraciones de la mucosa oral. ${ }^{1,34,38}$

\section{TRASTORNOS PLAQUETARIOS Y DE LA COAGULACIÓN}

Las PLA son fragmentos citoplasmáticos provenientes de una célula conocida como megacariocito, el proceso de formación de las plaquetas se denomina megacariopoyesis. ${ }^{43}$ Las alteraciones de PLA y de la coagulación pueden ser de etiología funcional, cuantitativa o hereditaria (Tabla 3).

\section{Alteraciones funcionales}

\section{Trombastenia de Glanzmann}

Es un trastorno cualitativo de la función plaquetaria causado por una anomalía en los genes de las glicoproteínas

Tabla 3: Trastornos plaquetarios y de la coagulación. 1,4,14,33,45-53

\begin{tabular}{|c|c|c|}
\hline & & Manifestaciones orales \\
\hline \multirow[t]{3}{*}{ Alteraciones funcionales } & Trombastenia de Glanzmann & $\begin{array}{l}\text { Hemorragia gingival espontánea, epistaxis y episodios intermi- } \\
\text { tentes de hemorragias gastrointestinales }\end{array}$ \\
\hline & Síndrome de Bernard-Soulier & $\begin{array}{l}\text { Equimosis, petequias en la piel y mucosas, epistaxis, y hemorra- } \\
\text { gia severa en traumatismos y procedimientos quirúrgicos }\end{array}$ \\
\hline & Enfermedad de Von Willebrand & $\begin{array}{l}\text { Gingivorragia espontánea y hemorragias prolongadas después de } \\
\text { una cirugía bucal }\end{array}$ \\
\hline \multirow[t]{2}{*}{ Alteraciones cuantitativas } & Trombocitopenia & $\begin{array}{l}\text { Petequias cutáneas, hemorragias gingivales espontáneas provo- } \\
\text { cando que los dientes presenten depósitos de color marrón debido } \\
\text { a la hemosiderina y a otros productos de desecho }\end{array}$ \\
\hline & Trombocitemia & Hiperplasia gingival secundaria a la administración de ciclosporina \\
\hline Trastornos de la coagulación & Hemofilia & $\begin{array}{l}\text { Hemorragias gingivales episódicas prolongadas, espontáneas o } \\
\text { traumáticas son las más frecuentes, entre las menos frecuentes es } \\
\text { la hemartrosis de la articulación temporomandibular }\end{array}$ \\
\hline Trastorno autoinmune & Trombocitopenia inmunitaria & $\begin{array}{l}\text { Hemorragia gingival espontánea, petequias, hematomas en zonas } \\
\text { sometidas a trauma (mucosa bucal, bordes linguales laterales y } \\
\text { el límite entre el paladar duro y el blando), aparecen vesículas } \\
\text { hemorrágicas principalmente en lengua, labios y la línea oclusal, } \\
\text { son de } 2 \text { mm de diámetro que no desaparecen a la presión, son } \\
\text { planos y asintomáticos }\end{array}$ \\
\hline
\end{tabular}


Ilb/IIla. Estos genes codifican para un grupo de proteínas enlazadas que se encuentran en la superficie de las plaquetas, el receptor glicoproteína IIb/IIla (también llamado receptor de fibrinógeno). La ausencia o el funcionamiento inadecuado del receptor provocan que las plaquetas no se adhieran entre sí en el sitio de la lesión y es difícil que se forme un coágulo normal. Como todos los trastornos autosómicos recesivos, se encuentra más frecuentemente en regiones del mundo donde son comunes los matrimonios consanguíneos. ${ }^{33,44}$ Las manifestaciones orales son gingivorragias espontáneas y sangrado excesivo después de un procedimiento quirúrgico. ${ }^{1,33}$

\section{Síndrome de Bernard-Soulier}

Es una enfermedad hereditaria que se caracteriza por una tendencia hemorrágica, PLA gigantes y en número disminuido. La incidencia se desconoce debido a la dificultad del diagnóstico y su reporte. El defecto subyacente es una deficiencia o disfunción de la glicoproteína GPIb-V-IX receptor para el factor de Von Willebrand, requerido para la hemostasia primaria. ${ }^{45,46}$ Sus manifestaciones orales son equimosis, petequias en la piel y mucosas, epistaxis, y hemorragia severa en traumatismos y procedimientos quirúrgicos. ${ }^{33}$

\section{Enfermedad de Von Willebrand}

Es un trastorno hemorrágico hereditario que se caracteriza por un defecto en la glicoproteína factor de Von Willebrand, el cual se sintetiza en las células endoteliales y en los megacariocitos. La alteración de estas glicoproteínas afecta el proceso de la hemostasia primaria (adhesión al subendotelio y agregación plaquetaria). Se asocia a mutaciones en el cromosoma 12 en la región p13.2, el cual codifica el factor de Von Willebrand. Es el trastorno hemorrágico hereditario descrito con mayor frecuencia y afecta a $0.1-1.3 \%$ de la población. ${ }^{46,47}$ Las manifestaciones orales son gingivorragia espontánea y hemorragias prolongadas después de una cirugía bucal. ${ }^{1,47}$

\section{Alteraciones cuantitativas}

\section{Trombocitopenia}

Es un trastorno caracterizado por la disminución de PLA en la circulación periférica. ${ }^{48}$ El rango normal es de $200.000-$ $400.000 / \mathrm{mm}^{3}$ y recuentos inferiores a $100.000 / \mathrm{mm}^{3}$ indican que el paciente cursa con trombocitopenia. ${ }^{49} \mathrm{Su}$ etiología puede ser debido a un descenso en la producción, producción ineficaz o aumento de la destrucción de plaquetas, pero puede ser un signo secundario a las siguientes condiciones: anemia aplásica, alcoholismo, quimioterapia, radioterapia, medicamentos citotóxicos (diuréticos, tiacídicos, ibuprofeno, tamoxifeno, fenitoína y ranitidina). ${ }^{4}$ Las manifestaciones orales son petequias cutáneas y hemorragias gingivales espontáneas, lo que provoca que los dientes presenten depósitos de color marrón debido a la hemosiderina y a otros productos de desecho. ${ }^{1}$

\section{Trastornos de la coagulación}

\section{Hemofilias}

Las hemofilias A y B son los principales trastornos de la coagulación, son de carácter hereditario y está ligado al cromosoma sexual $X$, en el cual se presentan mutaciones en los genes del factor VIII (hemofilia A, HA) y factor IX (hemofilia B, HB), lo que ocasiona una disminución o deficiencia funcional de estas proteínas en plasma y afecta la hemostasia secundaria. Su frecuencia es de uno en 5,000 y uno en 30,000 varones recién nacidos vivos, respectivamente, y afecta casi exclusivamente a varones, teniendo las mujeres portadoras un riesgo de $50 \%$ de heredarlo a sus hijos. ${ }^{50}$ Las manifestaciones orales dependen del tipo y severidad del déficit de factor. La clasificación por tipo de factor ausente es hemofilia A que presenta hemorragias gingivales espontáneas o traumáticas prolongadas, y en menor frecuencia se pueden presentar hemartrosis de la articulación temporomandibular y pseudotumores de la hemofilia, las cuales son inflamaciones quísticas progresivas producidas por hemorragias recurrentes y pueden acompañarse de signos radiológicos de afectación ósea. En la hemofilia $B$ se presentan similitudes con la hemofilia A. 1,4,51 En cuanto a la severidad, la Federación Mundial de Hemofilia la clasifica, dependiendo el porcentaje de actividad normal del factor en sangre, con rango normal (50-150\%), hemofilia leve (5-40\%), hemofilia moderada $(1-5 \%)$ y hemofilia severa (por debajo del $1 \%){ }^{52}$

\section{Trastorno autoinmune}

\section{Trombocitopenia inmunitaria}

La trombocitopenia inmunitaria, antes púrpura trombocitopénica inmunitaria, es una enfermedad autoinmunitaria adquirida de manifestación variable. Se observa en adultos y en pacientes pediátricos. La etiología puede ser por una reacción cruzada ante virus, medicamentos o vacunas, pero también está relacionado con la leucemia, VIH y lupus eritematoso sistémico. ${ }^{1,14}$ Causa destrucción de 
plaquetas mediada por anticuerpos $\lg G$ dirigidos contra antígenos de la membrana de la plaqueta y del megacariocito. ${ }^{4,33}$ Las manifestaciones orales como consecuencia del descenso de PLA provoca que el paciente presente gingivorragias espontáneas, hematomas en zonas sometidas a trauma (mucosa bucal, bordes linguales laterales y el límite entre el paladar duro y blando)., ${ }^{1,53}$

\section{CONCLUSIÓN}

Los trastornos hematológicos son alteraciones de uno o varios linajes hematopoyéticos con distinta etiología cada uno de ellos, pero su alteración tiene un reflejo a nivel sistémico. En la cavidad oral las coagulopatías son los principales signos que pueden presentarse, por lo que es muy importante que se realice un correcto y oportuno diagnóstico, a través de un detallado interrogatorio y una minuciosa exploración física del paciente. En caso de detectar alguna alteración que suponga un trastorno hematológico debemos remitir al paciente al hematólogo para que le dé un correcto tratamiento, y en la atención odontológica se debe tener una comunicación con el hematólogo e intervenir con el paciente en medidas preventivas para minimizar las complicaciones.

\section{BIBLIOGRAFÍA}

1. Bascones-Martínez A, Muñoz-Corcuera M, Bascones-llundain C. Manifestaciones clínicas de las hematopatías no neoplásicas en odontología. Med Clin (Barc). 2012; 139 (1): 18-24.

2. Castellanos JL, Díaz LM, Lee EA. Medicina en odontología: manejo dental de pacientes con enfermedades sistémicas. 3a ed. México, D.F.: Editorial El Manual Moderno; 2015.

3. Hasan S, Khan N, Siddiqui A. Plummer vinson syndrome-A premalignant condition-an overview of literature. UJMDS. 2013; 1 (1): 28-30

4. Delong N, Burkhart NW. Patología oral y general en odontología. 2a ed. Barcelona: Wolters Kluwer Health; 2013.

5. Ibañez-Mancera NG. Propedéutica y semiología en odontología. Barcelona: Elsevier; 2015.

6. Tortora GJ, Derrickson B. Principios de anatomía y fisiología. 11a ed. Madrid: Editorial Medica Panamericana; 2006.

7. Mérida FJ, Moreno EE. Manual para técnico superior de laboratorio clínico y biomédico. Madrid: Editorial Médica Panamericana; 2015.

8. Pastrana JD, García de Casasola GS. Fisiopatología y patología general básicas para ciencias de la salud. Barcelona: Elsevier; 2013.

9. Rodak BF, Fritsma GA, Keohane EM. Hematología: Fundamentos y aplicaciones clínicas. Buenos aires: Editorial Medica Panamericana; 2014.

10. Hall JE. Guyton y Hall, Tratado de fisiología médica. 13a ed. Barcelona: Elsevier; 2016.

11. Islas GM, De la teja AE, Bravo AL. Importancia de las enfermedades hematológicas en estomatología pediátrica, parte I de III alteraciones estomatológicas secundarias a trastornos eritrocitarios. Rev ADM. 2009; 65 (5): 44-47.
12. Neville BD, Damm DD, Allen CM, Chi AC. Oral and maxillofacial pathology. 4th ed. USA: Elsevier; 2016.

13. Donato H, Cedola A, Rapetti MC, Buys MC, Gutiérrez M, Parias NR et al. Anemia ferropénica, guía de diagnóstico y tratamiento. Arch Argent Pediatr. 2009; 107 (4): 353-361.

14. Chi AC, Neville BW, Krayer JW, Gonsalves WC. Oral manifestations of systemic disease. Am Fam Physician. 2010; 82 (11): 1381-1388.

15. Donato H, Piazza N, Rapettia MC, De Grandis S, Bacciedoni V, Fabeiro $M$ et al. Deficiencia de hierro y anemia ferropénica Guía para su prevención, diagnóstico y tratamiento. Arch Argent Pediatr. 2017; 115 (4): 568-582.

16. Goel A, Bakshi SS, Soni N, Chiavi N. Iron deficiency anemia and Plummer-Vinson syndrome: current insights. J Blood Med. 2017; 8: $175-184$

17. Donohue-Cornejo A, Guzmán-Gastelum DA, Constandse-Cortéz D, Gaitán-Cepeda LA, Reyes-Escalera C. Squamous cell carcinoma in the tongue and Plummer-Vinson syndrome A case report. Rev Odont Mex. 2011; 15 (3): 189-192.

18. Sanchez RR, Hani de Ardila A, Bestene AJ. Sindrome de PlummerVinson. Rev Col Gastoenterol. 2004; 19 (4): 288-290.

19. González de Canales S, Olmo LM, Disfagia Etiopatogenia, clasificación y clínica, Revisiones y actualizaciones. Medicine. 2000; 8: 1-6.

20. Silva DI, Assis CF, Costa BA, Evangelista CE, Falcão MM. PlummerVinson syndrome: a case report. Rev Col Bras Cir. 2013; 40 (1): 81-82.

21. Moreira VF, Garrido E. Megaloblastic anemia and atrophic gastritis. Rev Esp Enferm Dig. 2011; 103 (6): 332.

22. De paz R, Hernández-Navarro F. Manejo, prevención y control de la anemia perniciosa. Nutr Hosp. 2005; 20 (6): 433-435.

23. Contreras EZ, Rámirez-Cheyne JA, Vallejo-Serna RA, Zuñiga-Correa LP. Anemia perniciosa: descripción de un caso clínico. Rev Col Gastroenterol. 2008; 23 (1): 83-88.

24. Williamson MA, Snyder LM. Wallach Interpretación clínica de pruebas diagnósticas. 9a ed. Lippincott Williams \& Wilkins, 2012.

25. Feliu TA, Bonduel M, Sciuccati G, Del Pozo A, Roldán A, Ciaccio $M$ et al. $\beta$ Talasemia mayor en la Argentina. Med (Buenos Aires). 2002; 62: 124-134.

26. Chiappe G. Thalassemias: clinical aspects. Act Bioquim Clin Latinoam. 2017; 51 (3): 281-289.

27. Organización Mundial de la Salud. Talasemia y otras hemoglobinopatías. Informe de la Secretaría. OMS. 2006.

28. Cantalejo LM. Protocolo de anemia de células falciformes o drepanocitosis. Bol S Vasco-Nav Pediatr. 2005; 38: 20-38.

29. Zúñiga CP, Martínez GC, González RL, Rendón CD, Rojas RN, Barriga CF et al. Enfermedad de células falciformes: un diagnóstico para tener presente. Rev Chil Pediatr. 2018; 89 (3): 545-549.

30. Peñaloza-Espinoza RI, Buentello-Malo L, Hernández-Maya $M$, Nieva-García B, Liskev-Yurkowitzki R, Salamanca-Gómez F. Frecuencia de la hemoglobina Sen cinco poblaciones mexicanas y su importancia en la salud pública. Salud Pública Mex. 2008; 50 (4): $325-329$.

31. Soto AV, Lavados MM, Araya FD. Rash y anemia aplásica inducido por fenitoína: caso clínico. Rev Chil Neuro-Psiquiatr. 2011; 49 (2): 171-176.

32. Martínez JL, Ayala RD. Insuficiencia medular Anemia aplásica. Med. 2001; 8 (50): 2625-2631.

33. Islas GM, De la teja AE, Bravo AL. Importancia de las enfermedades hematológicas en estomatología pediátrica, Parte II de III alteraciones estomatológicas secundarias a trastornos leucocitarios. Rev ADM. 2009; 65 (6): 12-15. 
34. Shafer WG, Hine MK, Levy BM. Textbook of oral pathology. 7th ed. India: Elsevier; 2012.

35. Vargas-Casillas AP, Yáñez-Ocampo BR, Monteagudo-Arrieta CA. Periodontología e implantología. México: Editorial Médica Panamericana; 2016.

36. Oliva OK, Magaña VB, Fragoso RR, Cuairan VR. Cyclic neutropenia Clinical case report. Rev Odont Mex. 2015; 19 (4): 246-252.

37. Marsán-Suárez V, Pérez VL, Macías CA, Salgado LP, García Gl, Sánchez MS et al. Enfermedad granulomatosa crónica. Rev Cubana Hematol Inmunol Hemoter. 2014; 30 (3): 280-287.

38. Sanz-Sánchez I, Bascones-Martinez A. Otras enfermedades periodontales: I: Periodontitis como manifestación de enfermedades sistémicas. Av Periodon Implantol. 2008; 20 (1): 59-66.

39. Diz PD, Ocampo AH, Fernández JF. Alteraciones cuantitativas y funcionales de los neutrófilos. Med Oral. 2002; 7 (3): 46-61.

40. Camps MJ, Perdomo JH, Matos OC, Samón IR. Síndromes pediátricos con nombres raros. Rev Inf Cient. 2015; 93 (5): $1217-$ 1227.

41. Gallegos-Cisneros E, Cardiel-Silva M, Peral-Ibarra R, TavaresRodríguez EJ, Ávila-Chávez A. Síndrome de Chediak-Higashi en fase acelerada. Lux Med. 2015; 10 (31): 61-70.

42. Arulappan J, Shaji DT, Ahmed YW, Kumar SJ, Ramasamy MV. A child with Chediak-Higashi syndrome: A case study. Curr Pediatr Res. 2018; 22 (1): 69-72.

43. Rodak BF, Fritsma GA, Keohane EM. Rodak's Hematology. 5th ed. Philadephia: Elsevier; 2016.

44. Casas CP, Urrea FC, Solano MH, Sabogal MA. Manejo integral hematológico-odontológico en thrombastenia de Glanzmann. Act Med Colomb. 2015; 40 (1): 58-61.
45. Tripathi P, Karthika KV, Pati HP, Tyagi S. Bernard Soulier syndrome A rare bleeding disorder. IJMDS. 2018; 7 (1): 1642-1645.

46. Martínez-Murillo C. Enfermedad de Von Willebrand. El reto en el diagnóstico y el tratamiento. Rev Hematol Mex. 2018; 19 (2): 61-72.

47. Hernández-Zamora E, Zavala-Hernández C, Quintana-González S, Reyes-Maldonado E. Enfermedad de Von Willebrand, biología molecular y diagnóstico. Cir Cir. 2015; 83 (3): 255-264.

48. Taboada-Mascarin BI. Trombocitopenia inmunitaria primaria en niños. Rev Hematol Mex. 2018; 19 (2): 95-100.

49. Raspall G. Cirugía oral e implantología. 2a ed. México: Editorial Médica Panamericana; 2007.

50. Arango-Bernal YA. Significados de ser portadoras de hemofilia. Rev Cienc Cuidad. 2018; 15 (1): 18-33.

51. Meléndez EM. Farmacología y terapéutica en odontología: fundamentos y guía práctica. México: Editorial Médica Panamericana; 2012.

52. Federación mundial de hemofilia. Hemofilia, grados de severidad. Quebéc, 2012.

53. Alayón-Recio CS, Morfa-Viamontes FL, Rodríguez-Guerra YC, Heredia RE, Nodal ND. Manifestaciones bucales y cutáneas de la púrpura trombocitopénica inmunológica: reporte de un caso. Rev Arch Camagüey. 2018; 22 (1): 85-93.

Correspondencia:

Daniel Rodríguez Ortega

E-mail: dan_rodr14@me.com 